\title{
Perbandingan Spektral Musik Klasik dengan Musik Etnik Jawa menggunakan Analisis MFCC dan Beat Strength
}

\author{
Dody Kurniawan, Ahmad Syakir, Hana Afifah, ${ }^{*}$ Rayhan Hanina, Iwan Yahya, ${ }^{\dagger}$ dan Harjana \\ Laboratorium Riset Akustik (iARG) Jurusan Fisika, Fakultas Matematika dan Ilmu Pengetahuan Alam, \\ Universitas Sebelas Maret (UNS), Jl. Ir. Sutami 36A Kentingan, Surakarta 57126
}

Intisari

Analisis spektral dilakukan untuk membandingkan pola musik Jawa terhadap musik klasik karangan Mozart (1756-1791) dengan metode Mel Frequency Cepstral Coefficient (MFCC) dan Beat Strenght. Analisis MFCC menggunakan Hamming window dan konversi RGB menggunakan persamaan kemiripan dalam proses visualisasi. Analisis Beat Strenght berdasarkan nilai PEAK dan SUM pada Beat Histogram. Hasil analisis MFCC menunjukkan bahwa pola musik klasik dengan musik jawa mempunyai tingkat kemiripan 98,0\% untuk March of The Priests from The Magic Flute dan 90,3\% untuk Piano Sonata in C Major. Analisis Beat Strenght menunjukkan $89,8 \%$ kemiripan untuk March of The Priests from The Magic Flute dan 72,6\% untuk Piano Sonata in C Major.

\begin{abstract}
Spectral analysis between Javanese music and classical music by Mozart (1756-1791) using MFCC and Beat Strenght has been conducted. MFCC analysis using Hamming window and RGB conversion using similarity equation in visualization process. Beat Strength analysis based on PEAK and SUM value of Beat Histogram. The result shows that the pattern of classical music and Javanese music has 98.0\% similarity for March of The Priests from The Magic Flute and 90.3\% for Piano Sonata in C Major. Beat Strength analysis shows 89.8\% similarity for March of The Priests from The Magic Flute and 72.6\% for Piano Sonata in C Major.
\end{abstract}

KATA KUNCI: Mel Frequency Cepstral Coefficient, Beat Strength, Beat Histogram,similarity

\section{PENDAHULUAN}

Bunyi atau musik diyakini mampu mempengaruhi tingkat emosi dan suasana hati seseorang. Berdasarkan penelitian D. S. Berger dan D. J. Schneck [1] (ahli terapi musik di Virginia, Amerika Serikat), menggunakan musik untuk tujuan terapi ternyata bisa menghilangkan rasa takut dan stres. Penelitian oleh Halpern [2] juga membuktikan bahwa mendengarkan musik yang memiliki irama seperti detak jantung manusia (40 - 60 bpm) sangat cocok untuk relaksasi dan menenangkan pikiran. Hal tersebut diperkuat penelitian dari Campbell [3], bahwa musik klasik terbukti dapat meningkatkan fungsi otak dan intelektual manusia secara optimal.

Paper ini mencoba membuka potensi musik-musik tradisional Jawa dalam terapi musik dengan membandingkannya terhadap beberapa musik klasik karangan Mozart yang terbukti mampu memberikan efek Mozart, yaitu March of The Priests from The Magic Flute dan Piano Sonata in C Major

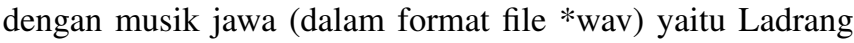
Harjuna Mangsah, Gendhing Lagu, Giro Kecak-Kecik, Ladrang Ayun-Ayun, Ladrang Balabak, Gendhing Tukung.

\footnotetext{
*E-MAIL: hana.afifah92@gmail.com

†E-MAIL: iyahya@mipa.uns.ac.id
}

\section{METODOLOGI}

\section{Proses ektraksi ciri MFCC}

Software Speech Filing System (SFS) 4.7 digunakan untuk ekstraksi MFCC. Ada beberapa tahapan dalam MFCC yaitu frame blocking, windowing, Discrete Fourier Transform (DFT) spectrum, Mel Scaling, dan DFT cepstrum. Frame blocking: tiap lagu dicuplik dalam beberapa frame dengan lebar yang sama. Windowing: menggunakan Hamming window. Sinyal suara kemudian diubah dari domain waktu ke domain frekuensi menggunakan Fast Fourier Transform (FFT), dengan 5 nilai FFT yang overlap pada posisi 0 , 441, 882, 1323, dan 1764. Mel Scaling: mendapatkan nilai log dari spektrum energi pada masing-masing frame [4]. Mel Scaling merupakan suatu algoritma yang merepresentasikan skala persepsi pitch yang dianggap sama antar pendengar $[4,5]$.

$$
\text { Mel-frequency }=2595 \log _{10}\left(\frac{1}{\frac{f}{700}}\right)
$$

Langkah terakhir yaitu inverse DFT untuk mentransformasikan kedalam bentuk koefisien cepstral sebanyak 16 [5]. 


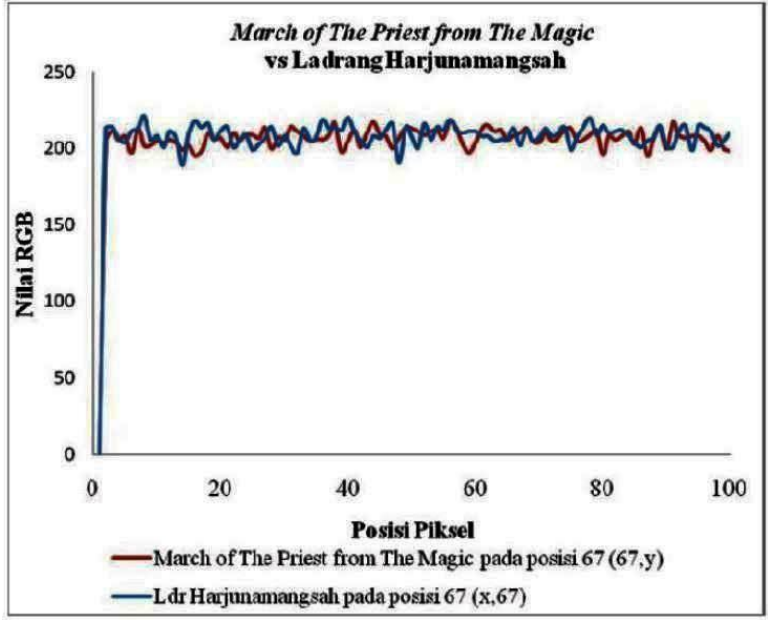

Gambar 1: Grafik perbandingan nilai RGB March of The Priests from The Magic Flute dengan Ladrang Harjuna Mangsah.

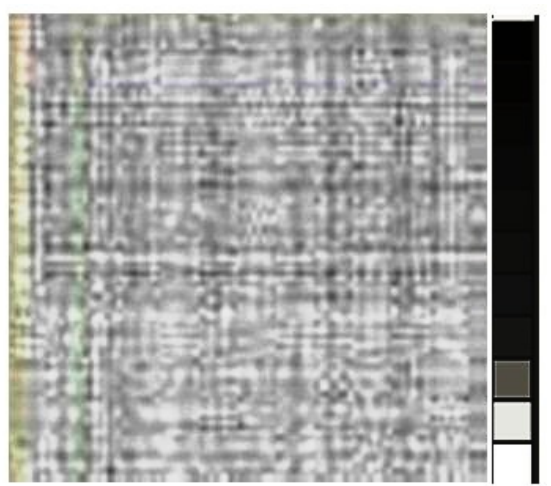

Gambar 2: Perpaduan nilai RGB March of The Priests from The Magic Flute dengan Ladrang Harjuna Mangsah.

\section{Proses visualisasi MFCC}

Pengukuran similarity berdasarkan vektor kesebandingan. Misalkan terdapat dua buah bentuk vektor MFCC, yaitu $\mathrm{v}_{i}$ dan $\mathrm{v}_{j}$ yang berskala dari frame suara $\mathrm{i}$ dan $\mathrm{j}$, maka suatu matriks sederhana dari persamaan vektor s adalah skalar (dot) product dari kedua vektor.

$$
s(i, j) \equiv v_{i} \bullet v_{j}
$$

dengan menggunakan nilai pengukuran similarity, suatu audio dapat divisualkan guna mengetahui tingkat kemiripannya. Dengan menggunakan software Borland Delphi 7.0 visualisasi ditampilkan dengan gambar 2D dalam format grayscale. Tingkat kemiripan suatu audio ditunjukkan dari intensitas kecerahan warna dari hitam ke putih. Semakin cerah warna yang ditunjukkan maka tingkat kemiripannya semakin tinggi.

\section{Analisis Beat Strenght}

Beat Strenght merupakan salah satu metode untuk merepresentasikan pola ketukan atau ritme audio berdasarkan nilai

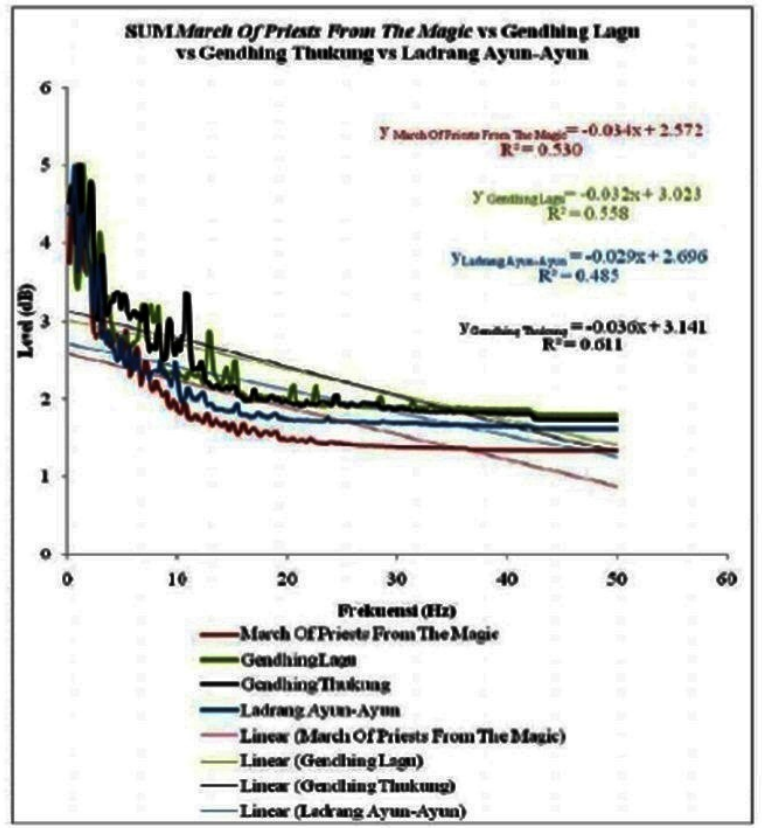

Gambar 3: Grafik nilai SUM March of The Priests from The Magic Flute vs Gendhing Lagu vs Gendhing Thukung vs Ladrang AyunAyun.

SUM dan PEAK dari suatu Beat Histogram. Beat Histrogram dibangun dengan menggunakan software Audacity. Sinyal audio dianalisis dalam domain frekuensi (fourier transform) dengan jendela Hanning $($ size $=512$ ). Nilai SUM diperoleh dari keseluruhan data Beat Histogram, sedangkan nilai PEAK diperoleh dari puncak-puncak yang terbentuk pada histogram [6].

\section{HASIL DAN PEMBAHASAN}

\section{Nilai RGB}

Nilai RGB menunjukkan level similarity antar audio yang dibandingkan. Range nilai RGB dimulai dari 0 hingga 255, dengan nilai RGB mendekati nol menunjukkan tingkat similarity yang rendah dan menunjukkan tingkat similarity yang tinggi pada nilai maksimum. Perbandingan rata-rata nilai RGB dari sampel lagu yang digunakan dalam penelitian disajikan dalam Tabel I dan Tabel II. Nilai RGB yang dibandingkan adalah pada posisi $(67,0)$ hingga $(67,100)$ dengan posisi $(0,67)$ hingga $(100,67)$ dari hasil visualisasi.

Berdasarkan Tabel I dan II, didapatkan rata-rata nilai RGB berkisar antara 182,58 hingga 207,58. Rentang nilai yang cukup baik dalam visualisasi similarity, dimana nilai mendekati maksimum. Pada Gambar 1 disajikan grafik perbandingan nilai RGB dan Gambar 2 visualisasi similarity antara March of The Priests from The Magic Flute dengan Ladrang Harjuna Mangsah. Pola yang dibentuk pada grafik 
TABEL I: Perbandingan nilai RGB March of The Priests from The Magic Flute dengan musik Jawa.

\begin{tabular}{|c|c|c|c|}
\hline No & Nama Musik & $\begin{array}{c}\text { Nilai } \\
\text { Rata-rata RGB }\end{array}$ & $\begin{array}{c}\text { Perbandingan } \\
\text { Rata-rata RGB }\end{array}$ \\
\hline 1 & $\begin{array}{l}\text { March of The Priests from The Magic Flute } \\
\text { Ladrang Harjuna Mangsah }\end{array}$ & $\begin{array}{l}204,99 \\
206,68\end{array}$ & 0,99 \\
\hline 2 & $\begin{array}{l}\text { March of The Priests from The Magic Flute } \\
\text { Giro Kecak- Kecik }\end{array}$ & $\begin{array}{l}200,19 \\
205,43\end{array}$ & 0,97 \\
\hline 3 & $\begin{array}{l}\text { March of The Priests from The Magic Flute } \\
\text { Gendhing Lagu }\end{array}$ & $\begin{array}{l}205,44 \\
207,57\end{array}$ & 0,99 \\
\hline 4 & $\begin{array}{l}\text { March of The Priests from The Magic Flute } \\
\text { Gendhing Tukung }\end{array}$ & $\begin{array}{l}197,09 \\
204,53\end{array}$ & 0,96 \\
\hline 5 & $\begin{array}{l}\text { March of The Priests from The Magic Flute } \\
\text { Ladrang Balabak }\end{array}$ & $\begin{array}{l}207,58 \\
205,98\end{array}$ & 0,99 \\
\hline 6 & $\begin{array}{l}\text { March of The Priests from The Magic Flute } \\
\text { Ladrang Ayun-Ayun }\end{array}$ & $\begin{array}{l}200,71 \\
205,35\end{array}$ & 0,98 \\
\hline
\end{tabular}

TABEL II: Perbandingan nilai RGB Piano Sonata in C major dengan musik Jawa.

\begin{tabular}{|c|c|c|c|}
\hline & Nama Musik & $\begin{array}{c}\text { Nilai } \\
\text { Rata-rata RGB }\end{array}$ & $\begin{array}{c}\text { Perbandingan } \\
\text { Rata-rata RGB }\end{array}$ \\
\hline 1 & $\begin{array}{l}\text { Piano Sonata in C major } \\
\text { Ladrang Harjuna Mangsah }\end{array}$ & $\begin{array}{l}188,13 \\
207,22\end{array}$ & 0,91 \\
\hline 2 & $\begin{array}{l}\text { Piano Sonata in C major } \\
\text { Giro Kecak- Kecik }\end{array}$ & $\begin{array}{l}187,65 \\
207,27\end{array}$ & 0,91 \\
\hline 3 & $\begin{array}{l}\text { Piano Sonata in C major } \\
\text { Gendhing Lagu }\end{array}$ & $\begin{array}{l}186,92 \\
207,58\end{array}$ & 0,90 \\
\hline 4 & $\begin{array}{l}\text { Piano Sonata in C major } \\
\text { Gendhing Tukung }\end{array}$ & $\begin{array}{l}182,58 \\
206,31\end{array}$ & 0,89 \\
\hline 5 & $\begin{array}{l}\text { Piano Sonata in C major } \\
\text { Ladrang Balabak }\end{array}$ & $\begin{array}{l}187,66 \\
206,61\end{array}$ & 0,91 \\
\hline 6 & $\begin{array}{l}\text { Piano Sonata in } C \text { major } \\
\text { Ladrang Ayun-Ayun }\end{array}$ & $\begin{array}{l}186,86 \\
207,32\end{array}$ & 0,90 \\
\hline
\end{tabular}

dalam Gambar 3, 4, 5, dan 6 menunjukkan rentang nilai RGB yang selaras satu sama lain dimulai dari posisi pixel 67 serta menampilkan kontras kecerahan yang tinggi untuk masing-masing frame yang dibandingkan.

\section{Nilai SUM analisis Beat Strenght}

Nilai SUM untuk musik klasik March of The Priests from The Magic dan Piano Sonata in $C$ dengan musik Jawa dapat dilihat pada Gambar 3 sampai dengan Gambar 6 . Nilai SUM ditunjukkan oleh gradient masing-masing grafik. Perbandingan nilai SUM antara musik klasik March of The Priests from The Magic dan musik jawa dapat dilihat pada
Tabel III dan Tabel IV adalah perbandingan nilai SUM antara musik klasik dan musik jawa. Perbandingan nilai SUM dapat digunakan untuk mengetahui kemiripan musik klasik dengan musik jawa.

Berdasarkan Tabel III maka music jawa yang mempunyai kecenderungan kemiripan dengan musik klasik March of The Priests from The Magic adalah Giro Kecak-Kecik dengan nilai perbandingan SUM sama dengan 1. Musik jawa yang jauh kemiripannya dengan musik klasik March of The Priests from The Magic adalah Ladrang Balabak. Adapun berdasarkan Tabel IV perbandingan nilai SUM dalam music jawa yang paling mirip dengan musik klasik Piano Sonata in $C$ adalah Ladarang Balabak dengan perbandingan nilai 
TABEL III: Perbandingan nilai RGB Piano Sonata in C major dengan musik Jawa.

\begin{tabular}{|c|c|c|c|c|}
\hline Nama Musik & $\begin{array}{l}\text { Nilai } \\
\text { SUM }\end{array}$ & $\begin{array}{c}\text { Perbandingan } \\
\text { Nilai SUM }\end{array}$ & $\begin{array}{c}\text { Nilai } \\
\text { PEAK }\end{array}$ & $\begin{array}{c}\text { Perbandingan } \\
\text { Nilai PEAK }\end{array}$ \\
\hline March of The Priests from The Magic Flute & 0,034 & & 0,049 & \\
\hline Ladrang Harjuna Mangsah & 0,039 & 0,87 & 0,048 & 0,98 \\
\hline March of The Priests from The Magic Flute & 0,034 & & 0,049 & \\
\hline Giro Kecak-Kecik & 0,034 & 1 & 0,061 & 0,80 \\
\hline March of The Priests from The Magic Flute & 0,034 & & 0,049 & \\
\hline Gendhing Lagu & 0,032 & 0,94 & 0,052 & 0,95 \\
\hline March of The Priests from The Magic Flute & 0,034 & & 0,049 & \\
\hline Gendhing Tukung & 0,036 & 0,94 & 0,055 & 0,90 \\
\hline March of The Priests from The Magic Flute & 0,034 & & 0,049 & \\
\hline Ladrang Balabak & 0,026 & 0,77 & 0,039 & 0,80 \\
\hline March of The Priests from The Magic Flute & 0,034 & & 0,049 & \\
\hline Ladrang Ayun-Ayun & 0,029 & $\begin{array}{c}0,85 \\
0,048\end{array}$ & & 0,98 \\
\hline
\end{tabular}

TABEL IV: Perbandingan nilai SUM dan PEAK Piano Sonata in C major dengan musik Jawa.

\begin{tabular}{|c|c|c|c|c|}
\hline Nama Musik & $\begin{array}{l}\text { Nilai } \\
\text { SUM }\end{array}$ & $\begin{array}{c}\text { Perbandingan } \\
\text { Nilai SUM }\end{array}$ & $\begin{array}{c}\text { Nilai } \\
\text { PEAK }\end{array}$ & $\begin{array}{c}\text { Perbandingan } \\
\text { Nilai PEAK }\end{array}$ \\
\hline Piano Sonata in C major & 0,019 & \multirow[b]{2}{*}{0,49} & 0,058 & \multirow[b]{2}{*}{0,83} \\
\hline Ladrang Harjuna Mangsah & 0,039 & & 0,048 & \\
\hline Piano Sonata in C major & 0,019 & \multirow{2}{*}{0,56} & 0,058 & \multirow{2}{*}{0,95} \\
\hline Giro Kecak-Kecik & 0,034 & & 0,061 & \\
\hline Piano Sonata in $C$ major & 0,019 & \multirow[b]{2}{*}{0,60} & 0,058 & \multirow[b]{2}{*}{0,90} \\
\hline Gendhing Lagu & 0,032 & & 0,052 & \\
\hline Piano Sonata in C major & 0,019 & \multirow{2}{*}{0,53} & 0,058 & \multirow{2}{*}{0,95} \\
\hline Gendhing Tukung & 0,036 & & 0,055 & \\
\hline Piano Sonata in C major & 0,019 & \multirow[b]{2}{*}{0,73} & 0,058 & \multirow[b]{2}{*}{0,68} \\
\hline Ladrang Balabak & 0,026 & & 0,039 & \\
\hline Piano Sonata in C major & 0,019 & \multirow{2}{*}{0,66} & 0,058 & \multirow{2}{*}{0,83} \\
\hline Ladrang Ayun-Ayun & 0,029 & & 0,048 & \\
\hline
\end{tabular}




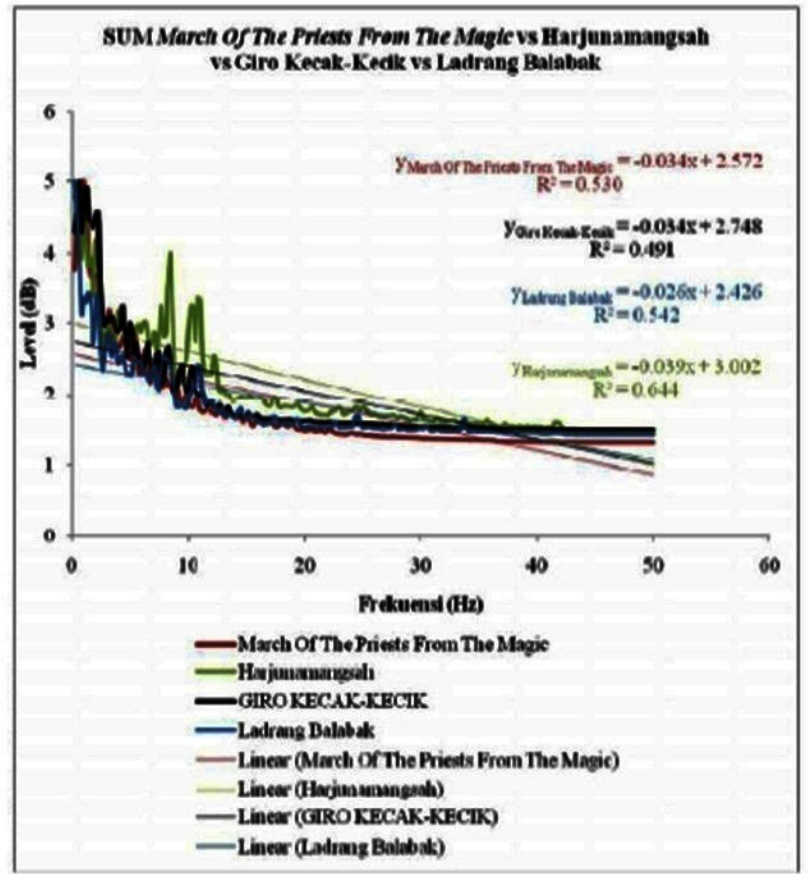

Gambar 4: Grafik nilai SUM March of The Priests from The Magic Flute vs Harjunamangsah vs Giro Kecak-Kecik vs Ladrang Balabak.

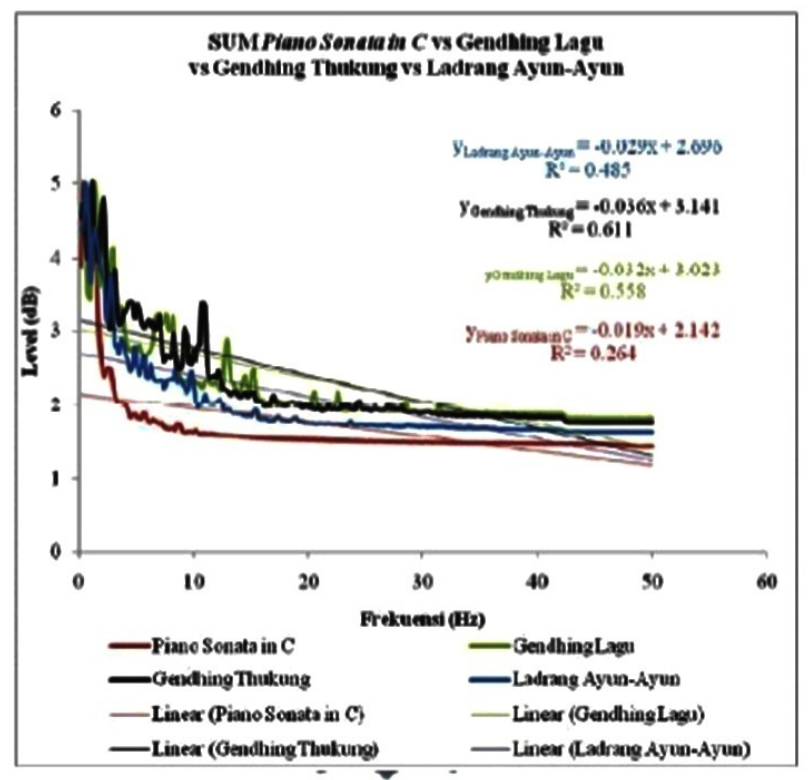

Gambar 5: Grafik nilai SUM Piano Sonata in $C$ vs Gendhing Lagu vs Gendhing Thukung vs ladrang Ayun-Ayun.

SUM mendekati 1, dan yang paling jauh kemiripannya adalah musik jawa Ladrang Harjumanangsah.
Dari Tabel IV juga dapat dilihat perbandingan nilai peak guna mengetahui kemiripan musik klasik dengan musik jawa. Berdasarkan Tabel IV musik jawa yang memiliki kemiripan dengan musik klasik March of The Priests from

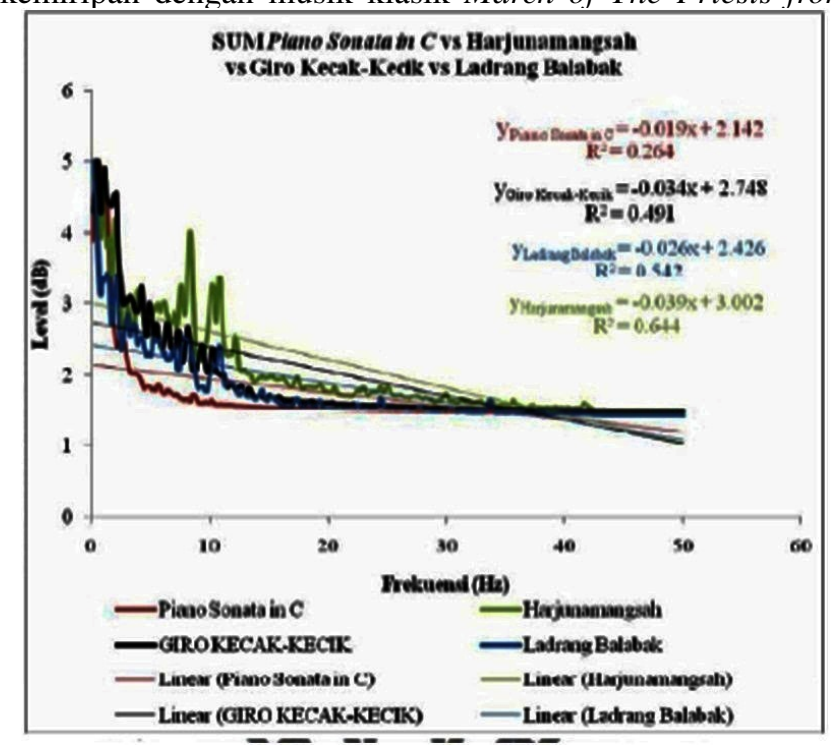

Gambar 6: Grafik nilai SUM Piano Sonata in $C$ vs Harjunamangsah vs Giro Kecak-Kecik vs Ladrang Balabak.

The Magic adalah Ladrang Harjumanangsah dan Ladrang Ayun-Ayun, sedang yang paling jauh kemiripannya adalah Giro Kecak-kecik dan Ladrang Balabak. Musik jawa yang memiliki kemiripan dengan music klasik Piano Sonata in $C$ adalah Giro Kecak-Kecik dan Gendhing Thukung, sedang yang paling jauh kemiripannya adalah Ladrang Balabak.

\section{SIMPULAN}

Hasil analisis spektral MFCC dan Beat Strenght, dapat disimpulkan bahwa musik tradisional Jawa (Ladrang Harjunamangsah, Gendhing Lagu, Giro Kecak-Kecik, Ladrang AyunAyun, Ladrang Balabak, dan Gendhing Tukung) memiliki kemiripan yang cukup tinggi terhadap musik klasik March of The Priests from The Magic Flute dan Piano Sonata in C Major. analisis MFCC menunjukkan bahwa pola musik klasik dengan musik jawa mempunyai tingkat kemiripan $98 \%$ untuk March of The Priests from The Magic Flute dan 90,3\% untuk Piano Sonata in C Major. analisis Beat Strenght menunjukkan adanya tingkat kemiripan $89,8 \%$ untuk March of The Priests from The Magic Flute dan 72,6\% untuk Piano Sonata in C Major.
[1] D.S. Berger, and D.J. Schneck, Journal of Scientific, 17 (4), 687703 (2003).
[2] S. Halpern, Perspective, 2, 4-6, (2005).

[3] D. Campbell, Efek Mozart(Gramedia Pustaka Utama: Jakarta, 
1998).

[4] J. Foote, Visualizing Musik and Audio Using Self-Similarity(FX Palo Alto Laboratory, Inc., USA, 1999).

[5] R.Vergin, D. P'Shaughnessy, and A. Farhat, Independent Continous Speech Recognitions, 7(5), (1999).
[6] G. Tzanetakiis, E. George, P. Cook, Human Perception and Computer Extraction of Beat Strenght, in Proc. Int. Conference on Digital Audio Effects (DAFX) Hamburg, Germany, September, 2002. 